\title{
The occurrence of Enterobacteriaceae producing KPC carbapenemases in a general hospital in Curacao
}

\author{
Sandra Erkens-Hulshof ${ }^{1,2^{*}}$, Liane Virginia-Cova ${ }^{3}$, Willemien van Dijk ${ }^{4}$, Juliette Severin ${ }^{5}$, Neil Woodford ${ }^{6}$, \\ Willem Melchers ${ }^{1}$ and Patrick Sturm ${ }^{1}$
}

\begin{abstract}
Background: Although the presence of Carbapenemase-producing Enterobacteriaceae (CPE) are extensively documented in North and South America. CPE have not been reported from Curacao. However, recently intercontinental spread was suggested of a KPC carbapenemase producing Klebsiella pneumoniae in a patient in the United Kingdom with previous admission to a hospital in Curacao in 2009.

Findings: After the introduction of the CLSI 2010 revised breakpoints, seven patients with carbapenemase-producing Enterobacteriaceae were found in a general hospital in Curacao over a period of 16 months. Four patients carried KPC-2 positive Klebsiella pneumoniae, ST11. Two patients carried KPC-3 positive Klebsiella pneumoniae ST258 and one patient carried a KPC-3 positive Citrobacter freundii. Furthermore, our Klebsiella pneumoniae KPC-2 ST11 strain was matched to the Klebsiella pneumoniae KPC-2 ST11 strain in the United Kingdom.

Conclusions: Introduction of new laboratory methods, and adoption of new guidelines and breakpoints led to the first detection of CPE in Curacao. By matching our Klebsiella pneumoniae KPC-2 ST11 strain to a Klebsiella pneumoniae KPC-2 ST11 strain in the United Kingdom, we suggest that carbapenemase-producing Enterobacteriaceae are probably more prevalent in Curacao than previously recognized.
\end{abstract}

Keywords: KPC, Carbapenemases, Enterobacteriaceae

\section{Findings}

Infections with carbapenemase-producing Enterobacteriaceae $(\mathrm{CPE})$ present clinicians with serious treatment challenges due to limited antibiotic options. They have been associated with high rates of mortality and morbidity, particularly in patients with severe underlying illnesses. The detection of CPE by routine susceptibility testing can be challenging, since the presence of carbapenem resistance genes does not always result in high-level resistance to carbapenems. More and more examples of patients with unrecognized CPE colonization are reported: these patients serve as reservoirs for transmission during health

\footnotetext{
* Correspondence: sandra.erkens@mumc.nl

'Department of Medical Microbiology, Radboud University Medical Centre,

Nijmegen, The Netherlands

${ }^{2}$ Department of Medical Microbiology, Maastricht University Medical Centre,

PO Box 5800, Maastricht 6202 AZ, The Netherlands

Full list of author information is available at the end of the article
}

care associated outbreaks, proving the need for rapid and adequate detection of CPE [1].

Several types of acquired carbapenemases have been detected in CPE, of which KPC, VIM, IMP, NDM and OXA-48-like enzymes are most prevalent. Since the detection of the first KPC isolate in 1996 in the United States [2] CPE have become widely distributed throughout the world including South America [3]. Until 2010 no $\mathrm{CPE}$ had been reported in Curacao, although intercontinental spread was suggested in a report of a KPC-producing Klebsiella pneumoniae isolated from a patient in the United Kingdom who had travelled to Curacao in 2009 [4]. Here we describe the occurrence of carbapenemaseproducing Enterobacteriaceae in Curacao after the introduction of the Clinical and Laboratory Standards Institute (CLSI) 2010 revised breakpoints.

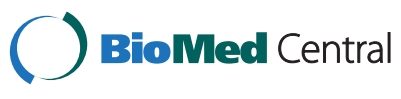

(c) 2014 Erkens-Hulshof et al.; licensee BioMed Central Ltd. This is an Open Access article distributed under the terms of the Creative Commons Attribution License (http://creativecommons.org/licenses/by/4.0), which permits unrestricted use, distribution, and reproduction in any medium, provided the original work is properly credited. The Creative Commons Public Domain Dedication waiver (http://creativecommons.org/publicdomain/zero/1.0/) applies to the data made available in this article, unless otherwise stated. 


\section{Methods}

St. Elisabeth Hospital in Willemstad, Curacao, is a 355-bed general hospital, providing care to patients from Curacao, and other islands of the Netherlands Antilles. It has fourteen general wards, a 6-bed coronary care unit and a 7-bed intensive care unit. The number of patient beds per room and presence of facilities such as bathroom and toilet differs between first, second and third class rooms. In first class patients have a private room with a private bathroom and toilet. Second class rooms are 2-4 bed rooms with the common use of bathroom and toilet. In third class there are 6-15 beds per room with the common use of bathroom and toilet.

All clinical samples are sent to the Analytic Diagnostic Centre for bacterial culture. Routine identification and susceptibility testing including detection of carbapenemases was according to CLSI standards using VITEK-1 until replacement by a VITEK-2 system in March 2010. With VITEK-2 lower screening breakpoints for the detection of CPE were introduced [5]. Decreased carbapenem susceptibility was confirmed by meropenem E-test and The modified Hodge test was performed.

From March 2010 - July 2011, all isolates with confirmed decreased susceptibility to carbapenems were sent to the Department of Medical Microbiology, Radboud University Medical Centre in the Netherlands. Confirmation of species identification was done by MALDI-TOF. Phenotypic investigations for carbapenemases included inhibition tests with 3-aminophenylboronic acid, clavulanic acid and EDTA. Based on the phenotype PCR for bla $\mathrm{K}_{\mathrm{KPC}}$ genes was performed and amplicons were sequenced. The presence of extended-spectrum beta-lactamase (ESBL) and AmpC genes was investigated by Check-MDR CT101 microarray (Check-Points, Wageningen, The Netherlands). Genotyping of isolates was performed using pulsed-field gel electrophoresis (PFGE) and multi-locus sequence typing (MLST) [6].

A K. pneumoniae strain isolated in the UK and suggestive of intercontinental spread from Curacao to the UK was also investigated [4].

\section{Ethical considerations}

This study is performed on routine clinical bacterial isolates and did not require the agreement of the ethical committee of our institution.

\section{Results}

In May 2010 the first carbapenemase-producing K. pneumoniae was detected from St. Elisabeth Hospital, Curacao. From May 2010 - July 2011, a total of seven clinical isolates were identified as CPE: six K. pneumoniae and one Citrobacter freundii. Both bla $\mathrm{KPC}-2_{2}$ and $\mathrm{bla}_{\mathrm{KPC}-3}$ genes were detected by PCR and sequencing (Table 1). Meropenem MICs ranged from 1 to $32 \mathrm{mg} / \mathrm{L}$. PFGE genotyping revealed an oligoclonal population of CPE (Figure 1). Four $\mathrm{K}$. pneumoniae isolates produced KPC-2 carbapenemase, belonged to ST11 and also produced a CTX-M group 1 ESBL. Two K. pneumoniae isolates with KPC-3 enzymes belonged to the international ST258 lineage, one of which also produced an SHV-type ESBL. Besides its chromosomal $\mathrm{AmpC}$, the $\mathrm{C}$. freundii isolate produced KPC-2 carbapenemase, but did not harbour any additional ESBL genes.

The PFGE patterns of the four KPC-2 producing $\mathrm{K}$. pneumoniae isolates were indistinguishable and were identical to that of the $\mathrm{K}$. pneumoniae isolate from the UK, which also produced KPC-2 and belonged to ST11 (Figure 1) [4].

\section{Patient information}

Five of seven carbapenemase producing Enterobacteriaceae were found on third class wards A, B and D, which are on the ground floor of the hospital. Ward A and B are localized in the west wing of the hospital. Ward D is in the east wing of the hospital.

The first K. pneumoniae KPC-3 ST258 discovered in May, was found in a patient admitted to ward A. This patient had been transferred from a hospital in Colombia. In October an identical strain was isolated from a patient in ward $\mathrm{B}$, but who had previously been admitted to ward A in May (Table 1).

Table 1 Details of patients from whom carbapenemase-producing Enterobacteriaceae was isolated

\begin{tabular}{|c|c|c|c|c|c|c|c|c|c|c|c|c|}
\hline Patient ID & Gender & $\begin{array}{l}\begin{array}{l}\text { Age } \\
\text { (years) }\end{array} \\
\end{array}$ & $\begin{array}{l}\text { Date of } \\
\text { positive } \\
\text { culture }\end{array}$ & Culture site & Species & Ward & Class & KPC & PFGE & MLST & $\begin{array}{l}\text { MIC } \\
\text { Meropenem }\end{array}$ & $\begin{array}{l}\text { Prior history of } \\
\text { hospital admission }\end{array}$ \\
\hline 1 & M & 58 & $6 / 5 / 10$ & Rectal surveillance & K. pneumoniae & A & 3 & 3 & B & 258 & 1 & Colombia \\
\hline 2 & M & 73 & $13 / 7 / 10$ & Urine & K. pneumoniae & B & 3 & 2 & A & 11 & 32 & - \\
\hline 3 & M & 15 & 24/8/10 & Urine & K. pneumoniae & C & 1 & 2 & A & 11 & 2 & - \\
\hline 4 & M & 77 & 26/10/10 & Urine & K. pneumoniae & B & 3 & 3 & $\mathrm{~B}^{\prime}$ & 258 & 1 & Ward A May 2010 \\
\hline 5 & M & 78 & $9 / 12 / 10$ & Rectal surveillance & K. pneumoniae & $\mathrm{D}$ & 3 & 2 & A & 11 & 4 & - \\
\hline 6 & M & 68 & $17 / 1 / 11$ & Wound & C. freundii & B & 3 & 3 & D & ND & 1 & Ward B Oct. 2010 \\
\hline 7 & M & 64 & 18/6/11 & Wound & K. pneumoniae & E & 2 & 2 & C & 11 & 8 & - \\
\hline
\end{tabular}

ND: not determined. 


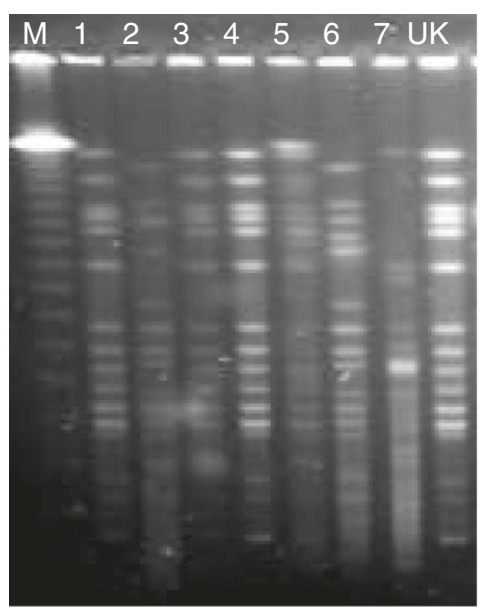

\begin{tabular}{ccc}
\hline Lane & Patient ID & PFGE \\
\hline $\mathbf{1}$ & 2 & A \\
$\mathbf{2}$ & 1 & B \\
$\mathbf{3}$ & 3 & A \\
$\mathbf{4}$ & 5 & A \\
$\mathbf{5}$ & 7 & C \\
$\mathbf{6}$ & 4 & B' \\
7 & 6 & D \\
\hline
\end{tabular}

Figure 1 PFGE profiles of seven KPC producing Enterobacteriaceae found in Curacao and the UK isolate. M: marker.

Moreover, the patient with $\mathrm{KPC}-3 \mathrm{C}$. freundii had been admitted to ward $\mathrm{B}$ at the time of positive culture of the second patient with $\mathrm{KPC}-3 \mathrm{~K}$. pneumonia in October. This patient was screened by the department of Hygiene Infection Control but found negative at the time.

There was no clustering in the hospital or time between the four patients with ST11 K. pneumoniae.

\section{Discussion and conclusion}

Dissemination of CPE has been described in several different countries in South America [7-9]. Results of this study show that CPE are present among clinical isolates in Curacao as well. Until then, no CPE had been detected on the island. However, in March 2010 a new VITEK-2 system was introduced with the CLSI 2010 revised breakpoints for Enterobacteriaceae, including the reduced breakpoints for carbapenem antibiotics. It seems likely that carbapenemaseproducing isolates have been present, but unrecognized before this update. This is supported by the report of Virgincar et al. who discussed the nosocomial transmission of a KPC-2 producing K. pneumoniae ST11 strain in the UK in 2009 , and which was probably introduced by a patient who had just been discharged from a hospital in Curacao [4].

In our study, the first patient with a $\mathrm{KPC}-3$ producing K. pneumoniae ST258 had recently been hospitalized in a hospital in Colombia, where an outbreak with similar organisms was described 2008 [10]. Since aggressive infection control has been shown to be effective in controlling dissemination of CPE, affected patients in our hospital were placed in contact isolation in single rooms, wherever possible. Strict compliance to hand hygiene for health care workers and family was advised by the Department of Hygiene Infection Control. However, nosocomial transmission may have occurred since the second patient with KPC-3 K. pneumoniae ST258 had been in the same ward as the first patient. Moreover, a third patient with KPC-3 producing $\mathrm{C}$. freundii had been previously admitted to the same ward as the second patient with KPC-3 K. pneumonia, which may indicate plasmid transfer between species as well as undetected KPC producers in one of the two or in both patients.

We have shown that the introduction of new laboratory methods, and adoption of new guidelines and breakpoints led to the first detection of CPE in Curacao. We suggest that carbapenemase-producing Enterobacteriaceae are possibly more prevalent in Curacao than previously recognized.

\section{Abbreviations}

CPE: Carbapenemase-producing Enterobacteriaceae; CLSI: Clinical and Laboratory Standards Institute; ESBL: Extended-spectrum beta-lactamase; PFGE: Pulsed-field gel electrophoresis; MLST: Multi-locus sequence typing.

\section{Competing interests}

All authors report no conflicts of interest relevant to this manuscript.

\section{Authors' contributions}

PS and SE were responsible for the acquisition and analysis of microbiological data, WD provided patient information and additional hygiene infection control measures. SE drafted the manuscript. JS provided and analyzed MLST data. WM provided and analyzed PFGE data. All authors read, reviewed and provided feedback on the final manuscript.

\section{Acknowledgements}

We thank Dr. N. Virgincar for providing the UK KPC-2 producing K. pneumoniae ST11 strain. We thank the Laboratory for Pathology and Medical Microbiology, Department of Medical Microbiology, Veldhoven, The Netherlands, for facilitating the analysis of the samples by the Check-MDR CT101 microarray. Further we thank C. Handgraaf and M. Laurens, for carrying out PFGE and MLST.

\section{Author details}

'Department of Medical Microbiology, Radboud University Medical Centre, Nijmegen, The Netherlands. ${ }^{2}$ Department of Medical Microbiology, Maastricht University Medical Centre, PO Box 5800, Maastricht 6202 AZ, The Netherlands. ${ }^{3}$ Analytical Diagnostic Centre, National Laboratory, Willemstad, Curacao, Netherlands Antilles. ${ }^{4}$ Department of Hygiene Infection Control, St. Elisabeth Hospital, Willemstad, Curacao, Netherlands Antilles. ${ }^{5}$ Department of Medical Microbiology and Infectious Diseases Erasmus MC, University Medical Centre Rotterdam, Rotterdam, The Netherlands. ${ }^{6}$ Antimicrobial Resistance and Healthcare Associated Infections Reference Unit, Public Health England, London, UK. 
Received: 13 March 2014 Accepted: 13 July 2014

Published: 1 August 2014

\section{References}

1. Woodford N, Tierno PM, Young K, Tysall L, Palepou MF, Ward E, Painter RE, Suber DF, Shungu D, Silver LL, Inglima K, Kornblum J, Livermore DM: Outbreak of Klebsiella pneumoniae producing a new CarbapenemHydrolyzing Class A $\beta$-lactamase, KPC-3, in a New York Medical Center. Antimicrob Agents Chemother 2004, 48:4793-4799.

2. Yigit H, Queenan AM, Anderson GJ, Domenech-Sanchez A, Biddle JW, Steward CD, Alberti S, Bush K, Tenover FC: Novel carbapenem-hydrolyzing beta-lactamase, KPC-1, from a carbapenem-resistant strain of Klebsiella pneumoniae. Antimicrob Agents Chemother 2001, 45:1151-1161.

3. Nordmann P, Naas T, Poirel L: Global spread of carbapenemase-producing Enterobacteriaceae. Emerg Infect Dis 2011, 17:1791-1798.

4. Virgincar N, lyer S, Stacey A, Maharjan S, Pike R, Perry C, Wyeth J, Woodford $\mathrm{N}$ : Klebsiella pneumoniae producing KPC carbapenemase in a district general hospital in the UK. J Hosp Infect 2011, 78:293-296.

5. Clinical and Laboratory Standards Institute: Performance Standards For Antimicrobial Susceptibility Testing. CLSI M100-S20. Wayne PA: CLSI; 2010.

6. Diancourt L, Passet V, Verhoef J, Grimont PAD, Brisse S: Multilocus sequence typing of Klebsiella pneumoniae nosocomial isolates. J Clin Microbiol 2005, 43:4178-4182.

7. Villegas MV, Lolans K, Correa A, Suarez CJ, Lopez JA, Vallejo M, Quinn JP, Colombian Nosocomial Resistance Group: First detection of the plasmidmediated Class A carbapenemase KPC-2 in clinical isolates of Klebsiella pneumoniae from South America. Antimicrob Agents Chemother 2006, 50:2280-2282.

8. Pasteran FG, Otaegui L, Guerriero L, Radice G, Maggiora R, Rapoport M, Faccone D, Di Martino A, Galas M: Klebsiella pneumoniae carbapenemase-2, Buenos Aires, Argentina. Emerg Infect Dis 2008, 14:1178-1180.

9. Monteiro J, Santos AF, Asensi MD, Peirano G, Gales AC: First report of KPC-2-producing Klebsiella pneumoniae in Brazil. Antimicrob Agents Chemother 2008, 53:333-334.

10. Lopez JA, Correa A, Navon-Venezia S, Correa AL, Torres JA, Briceño DF, Montealegre MC, Quinn JP, Carmeli Y, Villegas MV: Intercontinental spread from Israel to Colombia of a KPC-3 producing Klebsiella pneumoniae strain. Clin Microbiol Infect 2011, 17:52-56.

doi:10.1186/2047-2994-3-24

Cite this article as: Erkens-Hulshof et al:: The occurrence of

Enterobacteriaceae producing KPC carbapenemases in a general hospital in Curacao. Antimicrobial Resistance and Infection Control 2014 3:24.

\section{Submit your next manuscript to BioMed Central and take full advantage of:}

- Convenient online submission

- Thorough peer review

- No space constraints or color figure charges

- Immediate publication on acceptance

- Inclusion in PubMed, CAS, Scopus and Google Scholar

- Research which is freely available for redistribution 